\title{
Major Salivary Gland Cancer pT4b TNM
} Finding v7

National Cancer Institute

\section{Source}

National Cancer Institute. Major Salivary Gland Cancer pT 4b TNM Finding v7. NCI

Thesaurus. Code C89122.

Major salivary gland cancer with very advanced disease. Tumor invades skull base and/or pterygoid plates and/or encases carotid artery. (from AJCC 7th Ed.) 